\title{
CICLO DE CONVERSACIONES ANTROPOLOGÍAS DEL SUR: FRESIA SALINAS
}

\author{
PAULA CONTRERAS*, CLAUDIO ESPINOZA** \& LUIS CAMPOS***
}

\section{Resumen}

En esta cuarta entrevista del Ciclo de Conversaciones Antropologías del Sur, cuyo fin es revisar y pensar formas no hegemónicas de la disciplina, se presenta la trayectoria académica e intelectual de Fresia Salinas (Temuco, 1948), colega de destacada trayectoria en la antropología chilena. Como parte de la primera generación de egresados del departamento de antropología de la Universidad Católica de Temuco, Fresia nos comparte su visión de lo que fue estudiar antropología en los años setenta bajo el régimen dictatorial y sobre la importancia que tiene el trabajo de campo y la etnografía a lo largo de toda su trayectoria. La conversación nos conduce por los ámbitos temáticos abordados por Fresia Salinas, desde las reflexiones metodológicas hacia los estudios urbanos, donde destaca la etnografía colaborativa en el barrio Yungay; así como su rol en la Escuela de Antropología de la Universidad Bolivariana y en el Colegio de Antropólogos de Chile. Su relato es también una invitación a reflexionar sobre el presente y futuro de la antropología chilena.

* Académica Escuela de Antropología, Universidad Academia de Humanismo Cristiano, Santiago, Chile.

** Académico Escuela de Antropología, Universidad Academia de Humanismo Cristiano, Santiago, Chile.

*** Académico Escuela de Antropología, Universidad Academia de Humanismo Cristiano, Santiago, Chile. 
AdS: Fresia podríamos iniciar esta conversación pidiéndote que nos contaras de tus inicios, ¿dónde naciste? ¿dónde creciste y cómo llegaste a la antropología?

Nací en Temuco y estudié en Temuco, ¿y sabes qué? tuve la suerte, y aquí lo enlazo con esto de cómo llegué a la antropología, porque fue un interés desde muy pequeña. Mira, mi madre era profesora de francés, y le llegaban revistas y libros de Francia, y yo empecé a leer así de chica en francés, a empaparme un poco de la cultura esa, sin darme ni cuenta. Y mi padre era abogado y amaba a los mapuche. Entonces eso estuvo constantemente en mi casa, o sea, la conciencia de otros pueblos, de otras lenguas. Además, me pusieron en el Colegio Inglés de Temuco, las clases eran en inglés, excepto castellano, todo lo demás era en inglés, todo, hasta los juegos de los recreos eran en inglés. Entonces, estuve ahí en lo que se llamaba en ese tiempo "preparatoria" y después me fui al Liceo de Niñas Gabriela Mistral, por los intereses laicos de mi padre. Así que no fui al colegio de monjas porque mi padre lo prohibió determinantemente, esa habría sido otra cultura más, pero la desconocí. Pero pasé por varias miradas que me fueron dando el interés temprano por eso que existía más allá de los límites de mi pueblo o de mi ciudad, de mi país, de mi habla, de mi lengua. $Y$ así fue, esto fue derivando a que cuando me tocó dar la prueba para entrar a la universidad, lo que a mí me interesaba eran dos cosas: Leyes, que inicié en Concepción, y la segunda opción era Arqueología o Antropología. Y finalmente después de abandonar leyes, porque me pareció tan aburrida..., imagínate, yo tenía 16 años y me pareció fatal estudiar leyes. Mi padre, que era abogado, tampoco quería que yo estudiara leyes, encontraba que no era para señoritas porque había que ir a las cárceles y todas esas cosas típicas de una señorita provinciana, o sea ten en cuenta eso, el contexto era el de una señorita provinciana.

Entonces, después de eso me volví a Temuco, estudié castellano, Pedagogía en Castellano, que hoy día se llama Lenguaje y Comunicación. A través de eso llegué también, por lo menos inicialmente, al estudio de los clásicos. Y después de castellano me metí a antropología, pero ¿por qué? por la etnolingüística, porque había tenido lingüística con Alberto Salas, Lingüística, Romance y Griego, me parece, con él. Y cuando se abrió antropología como un Bachillerato en la Universidad Católica en Temuco, yo inmediatamente postulé porque quería seguir con Salas. Así que mi entrada a la antropología fue básicamente por la lingüística, aun cuando ya me interesaba por los llamados pueblos de la tierra. Así que, por ahí, más o menos, fue esta entrada por diversos ángulos a la antropología. Aparte de ese amor que tenía mi padre por el pueblo mapuche y a quienes a muchos de sus miembros él defendió en causas judiciales. Incluso, fíjate que mi tesis de licenciatura fue en antropología jurídica, o sea, en causas mapuche. Así que todo eso se juntó, toda esa historia se fue juntando para dar lo que dio.

AdS: Fresia y tú dices "me fui a la antropología siguiendo a Alberto Salas”, porque ahí en esos años en Temuco se crea un Centro, que es el CERER, y que convoca a gente como Martín Cordero, Alberto Salas, y que empieza a ser liderado por Milan Stuchlik que había llegado a la región. ¿Cómo podrías describir el ambiente intelectual que existía en Temuco por aquellos años? ¿Se reproducía allá lo que, por ejemplo, se estaba generando en Santiago con tantos exiliados que llegaban por esa época? 
En esa época, en los '70s, es que se abrió Antropología en la Católica de Temuco. Yo no creo haber participado en la intelectualidad regional ni local, sino que por mi padre. En mi casa había mucha conversa e iba mucha gente, había mucha discusión de filosofía, había una biblioteca extensa, pero yo no participaba. Lo que estaba en ebullición en ese tiempo, ustedes deben saberlo, en todo el país, era lo político. Eso era lo que yo recuerdo de esa época como más destacado, era la ebullición política. Fíjate que incluso a mí me tocó, date cuenta en los años, me tocó la Revolución del '68, que fue una revolución mundial, y era más o menos por estudiantes, de Francia, de hartas partes, y que llegó también a la Universidad Católica, antes de que yo entrara a Antropología. Entonces ahí había una cuestión que era política, ética si tú quieres, y donde estábamos todos metidos, incluso la gente que se decía apolítica, porque los había, pero nadie les creía, después entendí que podía existir eso, un apoliticismo. Pero estaban todos: "de dónde eres tú, cuál es tu proveniencia”, o sea, cuáles son tus ideas.

Eso era lo que más se discutía, y de todas maneras había teoría, había, digamos, eso de lo intelectual, claro había escritores, pero yo no tenía participación directa, sino que estaba ahí y dentro de la Antropología, en el CERER, había sí un trabajo importante desde el punto de vista teórico. Cuando Stuchlik se fue de Chile, se fue a Cambridge, nos escribía a nosotros, teníamos comunicación, y decía que nosotros estábamos, los estudiantes de ahí, estábamos teóricamente a la altura de los de Cambridge, pero no en lo práctico, es decir, no en la etnografía, porque los estudiantes ingleses o británicos se iban al África, a hacer sus tesis doctorales, y ahí hacían unas tremendas etnografías al estilo de los antiguos, qué sé yo, Evans Pritchard o alguno por el estilo. Pero teóricamente él nos había dejado en un nivel como internacional, por decirlo de algún modo. $Y$ en ese tiempo, en el tiempo que él estuvo, había mucha gente, no del exilio, pero venían, ponte tú, suecos a ver la situación extraña del socialismo chileno. También estaba Stephen Platt, sociólogo inglés, Maurice Hébert y Patrick Donovan, canadienses. Yo tuve un profesor noruego, que después se perdió en la Amazonía, nunca más supe de él, se fue a lquitos y se perdió por ahí en la selva en alguna parte. Tuve un profesor escocés, antropólogos todos, el profesor escocés se comunicaba conmigo después, se volvió loco, loco de verdad. O sea, era un conglomerado de gente. Tenía profesores norteamericanos. Entonces fue un ambiente muy rico en ese sentido, la gente discutía, discutía teóricamente, nosotros participábamos en eso como estudiantes, había mucho despliegue de eso. Pero Antropología en el CERER, más allá de eso, yo creo que, como alguien dijo, nosotros estábamos viviendo como en una especie de burbuja dentro del ámbito regional, porque si bien todo el mundo estaba, o casi todo el mundo estaba interesado en los procesos políticos de la época, nosotros estábamos interesados más allá todavía, en la cuestión de los procesos sociales, en la discusión... bueno, yo creo que tenía que ver con que la mayor parte de los profesores eran extranjeros, entonces su mirada era necesariamente un poco distinta, distintas a las propias de la región, para no decir del país. Entonces ese sería el medio en que nosotros nos criamos.

AdS: Hay un artículo que escribió Héctor Mora sobre el proceso de institucionalización de la antropología en Temuco, y claro, él nombra a Olaf Jansen, Maurice Herbert, Stephen Plath, el matrimonio Melville... 
Thomas y Marjorie, una maravilla. Fíjate que ahí, eso es bien interesante, eso tiene que ver con las personas que fueron influyentes, como los maestros. Yo reconozco a Salas primero, porque fue anterior a la antropología, y Salas, entre otras cosas, hizo el doctorado en Estados Unidos mientras hacía clases en Antropología. Después fue director. Entonces nos trajo toda la etonometodología, toda esta cosa nueva en la época, la llevó directo de sus clases, de sus clases como alumno a las clases que él hacía a nosotros como profesor. Entonces eso fue súper importante para mí, toda la línea de la etnolingüística fue súper importante. Después está Stuchlik, para qué te voy a decir, pero fíjate que Stuchlik para mí fue lo que se concibe como un maestro en el sentido global, o sea, para mí no fue solo un profesor. Nos reuníamos en su casa, nos invitaban a comer, salíamos con ellos a festejos, íbamos, no sé, a Chol Chol a pasear el grupo grande, con toda la gente. Para mi Stuchlik es bien importante en el caso de mi mirada antropológica, porque es como la etnografía que uno hace, que es una etnografía con el cuerpo, con todo, con el sentimiento, ¿te fijas?, no es la etnografía medio cuantitativa por así decirte, sino que es esa que una la vive encarnada. Y él era un hombre de familia, para mí eso era maravilloso, o sea, no era el profesor que era un profesor muy seco, duro, no era simpático ni nada por el estilo, pero él era un hombre de familia, entonces toda su familia participaba, y eso me gustaba mucho, o sea, me gustaba ver al hombre completo, no al profe suelto no más, sino que el hombre completo.

Así que fue en ese sentido un maestro, alguien que tenía un conocimiento y un pensamiento respecto del tema disciplinario, pero además tenía una manera de vivir, de vivir su vida personal que se entrecruzaba con otras cosas. Y después estuvieron los Melville, fíjate que si Salas fue para mí la lingüística, y la etnolingüística principalmente, Stuchlik fue esa completitud del maestro, antropólogo persona, y los Melville fueron tanto la filosofía, digamos la epistemología antropológica por el lado de Tom, como la práctica, la antropología aplicada por el lado de Marjorie (Margarita). No sé si ustedes saben que ellos fueron sacerdote y monja en su vida anterior. Pero Margarita fue una maestra también, una mujer que sería muy largo contar las cosas que pasaron con ellos antes. Ella era una antropóloga interesada en el servicio a los demás desde la antropología. Entonces, nos inculcó también esa parte de la antropología cultural aplicada norteamericana, aunque ella había vivido mucho tiempo en México. Stuchlik no era un teórico puramente así no más, él también estaba interesado en los procesos sociales contingentes, en lo que ocurría en la región, en lo que ocurría con los mapuche que fueron sus amigos, no fueron solo unos objetos, o sujetos de estudio, fueron también sus amigos.

Entonces, esos fueron mis maestros de la época, los maestros vivos, aparte de los maestros de libros, como Levi- Strauss, que me gustaba mucho y cuantos otros más. Pero esos fueron, digamos, entre el rol teórico, la persona humana que vive esta antropología, una actitud ética aplicada, todo eso me dieron, un compromiso con la disciplina, pero también desde el punto de vista de todos estos profesores con el alumno, no era un compromiso formal. Fíjate que Stuchlik, cuando yo hice mi tesis, que la hice con René San Martín, un antropólogo muy inteligente que venía de Francia, llegó después de que pasó lo del '73 y se fue Stuchlik, pero había venido por intermedio de Stuchlik, había llegado a Chile. 
René, no sé qué sería de él, pero él tenía una mirada, y voy a algo con esto, una mirada afrancesada, distinta de Lévi -Strauss, que también fue importante, él se fue a Valdivia después, y nunca terminó su doctorado, él estaba haciendo sus estudios doctorales con machis. No terminó porque yo creo que finalmente se comprometió y eso yo creo que le pasa a tanta gente, se comprometió con lo administrativo, se fue agarrando con lo administrativo, o no sé, enganchando, y quedó ahí su estudio y su posibilidad, diría yo, de entregar el conocimiento enorme que tenía y la inteligencia muy viva que tenía. No sé qué pasó con él, como les decía, pero ese fue mi profesor guía. Sin embargo, aunque tenía este profesor guía yo le mandaba a Stuchlik mi trabajo, y él me escribía, imagínate en esa época donde no había internet, se mandaban los documentos por barco más o menos, porque por avión era muy caro, y él me mandaba sus comentarios, prácticamente línea por línea. Mis propios alumnos después reclamaban porque yo era tan detallista, bueno, lo saqué de ahí..., jlínea por línea!

¿Te fijas? Entonces él estuvo comprometido con sus alumnos de todas partes, yo creo que hasta el momento de su muerte. Entonces eso es lo que yo aprendí en ese tiempo en CERER. Aprendí hartas cosas, y aprendí de antropología, pero también de otras áreas, pero esas otras áreas que para mí son entrelazadas, eso me dio una manera de pensar antropológica que no es solo antropológica, aun cuando con el tiempo, con el correr del tiempo, se fue incorporando todo eso en una antropología más contemporánea, que se enfatiza, creo yo, en el siglo XXI con la autoetnografía, que ha llegado a ser autoetnografía colectiva. O sea, no se quedó en la autoetnografía así no más, del yo, yo, yo, del solipsismo que decían algunos, sino que fue dando pie para esta etnografía colectiva que en algún momento se estuvo desarrollando, en el estudio de antropólogos y antropólogas de organizaciones. Bueno pero ya me estoy yendo por las ramas.

AdS: En relación a los Melville mencionaste el tema de la autoetnografía, y uno de los trabajos memorables que encontramos, es un trabajo que no fue publicado, que estaba editado, creemos, a máquina de escribir, y que lo publicaron ellos con la gente de la isla Huapi, que se llamaba "Memorias de la Isla Huapi", y que fue un trabajo en donde casi todos los autores son de la isla. Nos sorprendió porque era el primer texto que veíamos en donde los antropólogos no figuraban como autores, sino que figuraba toda la comunidad. ¿Te tocó ir a esos terrenos, participaste allá?

No..., y ahí viene la antropología urbana.., a mí me tocó hacer un trabajo con Margarita en la JUNAEB ${ }^{1}$. Además de mi trabajo jurídico, de antropología jurídica, que fue más bien documental en el último juzgado de indios que hubo, con el último juez de indios que hubo en Temuco. Antes, en realidad, con Marjorie, con Margarita, me tocó hacer un trabajo con lo que pasaba con la JUNAEB. Pero en el trabajo de ellos no nos tocó a nosotros participar. Claro que conocíamos, y existía esa impronta comunitaria, colectiva.

Por el lado teórico estaba Thomas, pero por el lado práctico aplicado era Marjorie. O sea, ahí había una diferencia complementaria entre los dos. A Thomas le interesaba clasificar, entre otros ejemplos, en qué tipo de antropología estaba Stuchlik, desde el punto de vista teórico y epistemológico, qué antropología era esa; pero 
a Marjorie le interesaba más las personas directamente y lo que ocurría con eso. O sea, ahí hay una complementariedad fantástica, entre estos dos personajes tan distintos. $Y$ lamentablemente a nosotros no nos tocó eso, pero nos tocaron los... no los resabios, sino que los chispazos de todo ese trabajo que ellos hacían. Incluso trabajos posteriores de ellos, de cosas que pasaron aquí, en Chile quiero decir, en la región, o que ellos construyeron en la región, no estuvieron a mi alcance. Después nos comunicábamos, con Margarita especialmente, y yo traté de acceder a trabajos de ellos y no pude. A lo mejor ahora están en internet.

AdS: $Y$ en ese contexto que nos cuentas, nos podrías decir cuáles eran las líneas de investigación que se desarrollaban en ese tiempo, qué investigaciones se estaban haciendo, cuáles eran las líneas en ese momento en que estaba desarrollándose la antropología.

Mira, yo creo que la mayoría de los profesores venían de afuera a hacer estudios con los mapuche. El foco era la sociedad mapuche. La sociedad en antropología social, ustedes son muy jóvenes, pero en algún tiempo la antropología era antropología social como sociología aplicada a los pueblos primitivos. A lo mejor por ahí, en sus estudios iniciales, escucharon eso. O la cultura si ustedes quieren, los norteamericanos usan cultura, en ese tiempo, preferentemente. Pero la mayoría eran europeos como Stuchlik, y lo que venían a hacer era estudiar el sistema económico, el sistema político mapuche, porque los mapuche eran una gran sociedad americana, desde el punto de vista de la gente de afuera, de los antropólogos de afuera, o sea, digna de estudio de verdad. De verdad, quiero decir que era digna de verdad de estudio, no que fuera cualquier otro tipo de significado.

¿Qué otra cosa se estudiaba? Había un sociólogo que estaba estudiando con el Doctor Martin Cordero, psiquiatra, me parece que alguno de ustedes lo nombró; estudiaba la sección psiquiátrica del hospital. Bueno, el mismo René San Martín, que vino a estudiar religión, chamanismo más bien. Bueno Stuchlik con sus estudios entre historia y actualidad de la época de los mapuche, a él le interesaban los procesos históricos también, con esto de las reducciones, lo que había significado el paso de la libertad anterior o semi libertad, al reduccionismo.., ese tipo de cosas se estudiaban.., básicamente eran los mapuche.

El mismo Salas estudió durante mucho tiempo la lengua mapuche. Fíjate que Salas, cuando lo nombraron en la Academia de la Lengua Chilena, hizo su presentación y habló en extenso de don Manuel. Don Manuel era su informante, pero era su amigo, era su partner. Él habló, ¿sabes?, casi se me caen las lágrimas en este mismo preciso instante, pero él habló del corazón, él habló del alma, habló de don Manuel que le entregó tanto, que le permitió, por último, si tú quieres, llegar a donde llegó Salas, aunque no se dedicó solo a lo mapuche, a la lengua mapudungun. Entonces eso también fue una cuestión súper linda, o sea, cómo el estudioso, te digo en masculino porque era Salas no más, el estudioso se involucra desde todos los aspectos con la persona con quien está trabajando, te fijas, es un trabajo colaborativo, también eso me quedó. Después lo pesqué del feminismo que también hace toda esta metodología colaborativa..., pero eso era también una parte de aquello que yo aprendí ¿te fijas? Si tú quieres una relación de sujeto a 
sujeto, que yo diría, más bien, una relación de personas integrales con personas integrales. Entonces esa parte para mí fue una preciosidad de manifestación de aquello que era estudiar Ciencias Sociales o, si tú quieres, de ser cientista social, no una distancia, sino que un entrelazamiento de personas que colaboran en pro del conocimiento.

Mira, yo siento que una persona que es profesora, que soy profesora, nunca termina de aprender, o sea, la persona que aprende, o trata de aprender más, es un profesor. Tú estás en constante aprendizaje, me siento, me sentía, ya que estoy retirada casi totalmente, me sentía más como eso que dicen facilitadora, que una profesora que enseña desde una carrera, sino que más bien del círculo ese, del círculo mágico ese que se arma, cuando tú estás con otro compartiendo.

AdS: Fresia, es muy interesante lo que estás contando, surgen veinte mil preguntas. Un especialmente relevante es sobre qué concepción tenían de la etnografía, cómo hacían etnografía y sobre todo cómo los introducían a ustedes en la etnografía. Cómo planificaban los trabajos de campo, si iban en grupo, si era obligatorio hacer trabajo de campo, cómo era ese proceso.

Mira hay hartas aristas en la posible respuesta, voy a empezar por atrás. Nos obligaban a hacer trabajo de campo, había que hacer trabajo de campo, claro. La primera vez que me tocó fue en Temuco, con una especie de tesina, también en antropología jurídica. Me acuerdo que me dio jaqueca, porque Stuchlik y su señora Jarka, que es muy querida, amiga hasta el día de hoy, me llevaron al Café Central para decirme que tenía que hacer este trabajo de campo, y me convenía hacer eso porque mi padre era abogado, conocía a todos los jueces, entonces era fácil entrar en ese medio. Me dolió la guata, me dolió la cabeza, me dio jaqueca, así que esa parte era obligada, pero lo obligado era con dulzura, te fijas, ellos me llevaron al café a tomar algo, no fue ya: a usted le toca bla, bla, bla. Después había trabajo de campo entre todos, que eran trabajos con paseo, no era trabajo de campo así todos sentados en una fila de sillas y el profesor adelante, no, había paseo, había trago, no para mí porque soy abstemia lamentablemente, por eso estoy tan joven como ustedes me pueden ver, jajaja (risas). Había festejo, pero festejo con las diferencias culturales del festejo; me acuerdo que algún norteamericano decía "ustedes chilenos tienen una manera rara de festejar con bailes y cosas así". No había baile, había conversa más bien, ese era el festejo en el trabajo de campo. Entonces me acuerdo uno en que por primera vez yo conocí las tumbas mapuche, que eran sarcófagos, en un valle por ahí cerca en la región, relativamente cerca de Temuco, entonces íbamos en conjunto, pero al mismo tiempo, todos estos otros profesores iban por su cuenta, como les decía algunos estaban haciendo sus tesis doctorales, y contaban en la clase, o sea no eran clases de "el libro tanto y el libro tanto".

Yo creo que cualquier antropólogo que da la clase o cualquier antropóloga que da la clase hace lo mismo, o sea, cuenta sus experiencias, esto que dice el libro aquí, sí, pero lo que yo viví también. Bueno quizás yo esté hablando desde el punto de vista del método, que debe haber sido como una línea que debo haber seguido durante muchos años. Pero era una introducción a la etnografía desde aquí. Yo no recuerdo fíjate, pensando en la primera cosa 
que tú me mencionaste, yo no recuerdo que haya sido más énfasis en la etnografía por Stuchlik, porque él, claro, era un etnógrafo macanudo, súper bueno, pero a él le interesaba más la cosa teórica y epistemológica, ese era su fuerte. Yo creo que la etnografía es... fíjate que pensando en un libro que él escribió con un colega suyo, que fue su amigo y colega durante mucho tiempo en Checoslovaquia y después en Inglaterra, ellos escribieron sobre los ejemplos etnográficos para la teoría, ¿se nota el énfasis? En cambio, para mí no es un ejemplo etnográfico, es una etnografía con un trasfondo teórico. O sea, todo eso que publiqué, que fue muy poco, más bien lo que escribí, harto escribí, fueron informes de investigaciones que había que hacer mandadas por instituciones del Estado u otras instituciones, todo eso era etnografía, descripciones, eran largas, pero con una impronta teórica que no necesariamente tenía que aparecer explícita. O sea, ponte tú, en el Barrio Yungay hay una teoría clarísima para mí, pero no está expresada en palabras, no está escrita, porque efectivamente, si vamos a temas más profundos en la antropología, efectivamente para mí no es solo el conocimiento, sino que la forma de conocer que es la episteme, o sea, epistemología en este caso, y es la mirada, el enfoque, la aproximación, lo que te da el sustento, son los pilares de cualquier descripción. O sea, una descripción de sentido común tiene pilares que están aquí, aunque tú no le pongas ni epistemología ni teoría, pero en antropología evidentemente que una etnografía tiene que tener un pilar de esos, o si no, está ajena a la disciplina. No digo que la disciplina sea todo en el mundo, ni que la gente que escribe novelas no sea maravillosamente etnográfica, para mí en lo personal, la etnografía se hace desde un fundamento, eso ha sido para mí la etnografía, y me parece que eso tiene que ver con lo que preguntabas. O sea, era una etnografía no obligada que se aprendió por los discursos vividos de los profesores, hablo de los profesores porque en general eran hombres..., tuvimos a Ximena Bunster también, quien nos hizo un curso sobre mapuche, si ahora que me acuerdo, ella fue la mujer que nos hizo clases también, aparte de Margarita que ya se las he mencionado.

AdS: Dos preguntas para, quizá, cerrar esta etapa de Temuco. Lo primero sería una mención a un hecho insoslayable, y es que la licenciatura en Temuco, según recordamos del texto de Mora, se abre en 1973, es decir que la licenciatura en Temuco comenzó y al rato viene la Dictadura, entonces una primera pregunta sería ver si tu recuerdas cómo eso afectó, o cómo impactó la Dictadura, o cómo se veía la Dictadura desde la antropología de Temuco etc. Eso es una primera cosa.

La licenciatura empezó el '74, cuando se fue Stuchlik, porque lo que nosotros sacamos con Stuchlik fue como un Bachillerato, que fue formalizado, yo te diría laxamente, con un Diploma, una cosa así. Y después, bueno, los planes eran antes de que viniera toda esta hecatombe de la dictadura, del golpe; los planes eran hacer la licenciatura, formalizarla, o sea, estaban todos los planes hechos, profesores, etc., y para el '73, entre otras cosas, allanaron la casa de los Stuchlik y de otros profesores y se fueron todos. Entonces ya estaban los planes y se siguió con la Licenciatura al año siguiente, pero de la manera más precaria, con nosotros, o sea la gente que tenía ya un título universitario, como Teresa Durán, que era profesora y asistente social, había estudiado Trabajo Social, y yo que era 
profesora de castellano, pedagoga, y que habíamos pasado por este Bachillerato que era como un intensivo. Entonces ahí empezó, el '74, loquísima, una cosa tan paradojal que imagínate una disciplina como la antropología social, que incluso tuvo que cambiar de nombre, porque se transformó en Sociocultural para matizar un poco lo de "social", que sonaba rojo, social sonaba socialista $y$ socialista sonaba a comunista, y comunista sonaba a rojo, rojo, rojo, o sea prohibido, tabú. Entonces se transformó en esta antropología sociocultural con una mención que se estudió bastante, los profesores trabajaron esa idea, mención en etnolingüística, porque eso parecía lo más fuera de este mundo por así decirlo, no contingente, no politizado, nadie sabía lo que era la etnolingüística. Pero imagínate lo que significa, tan paradojal en realidad, que esta carrera, esta disciplina, se instaure en dictadura con toda esa carga que tenía, o sea nosotros fuimos sospechosos, cambió la gente totalmente de la Universidad Católica. El Rector de la época que, de hecho, era vecino de una casa más allá de la mía, incluso alguna vez nos llevó él en auto a terreno, yo creo que porque quería saber qué diablos era lo que estábamos haciendo. En una época en que había que pedir permiso a los carabineros para salir, no era fácil, o sea, estar ahí en una región tan sumamente momia, porque era la región más momia de Chile, no voy a decir momia, conservadora, donde pasaron, es que ni te digo las cosas que pasaron, bueno, yo las viví, no me quiero ni acordar. Bueno, ahí estuvimos haciendo antropología desde la docencia, pero también con investigación. No me puedo olvidar de cuando se inició la licenciatura, porque yo participé como docente y también como alumna; o sea, yo me metí con un par de otros alumnos, todo el resto se desbandó.
Los que terminamos ahí fuimos Teresa Durán, que después se fue a estudiar el doctorado con Stuchlik, y Héctor Zumaeta que se dedicó más bien al tema de los museos, y yo, los tres quedamos de la primera generación. Bueno, ahí se formalizó la licenciatura y vinieron lo que alguna alumna llamó los tiempos oscuros, yo lo tomé eso y lo presenté, me acuerdo en algunas ocasiones por el Colegio de Antropólogos, como los tiempos oscuros.

Estudiar fue bueno, fue interesante, fue estar metidos como en un microclima, un microclima óptimo para las plantas, estas plantas humanas. En ese tiempo, en algún momento después, llegó Tom Dillehay, que llegó a Chile vía la Universidad Católica de Temuco, después se fue a Valdivia y era muy bueno estudiar ahí, si siempre fue bueno estudiar ahí. Lo difícil fue hacer investigaciones, y nosotros hacíamos investigaciones, o sea nunca fuimos antropólogos de poltrona, éramos investigadores que salíamos al campo, y ahí teníamos que tener una credencial con un permiso de carabineros, y nunca estabas seguro, o segura. Afortunadamente no nos pasó nada yo creo porque era la Universidad Católica, quizás fuera ese el paragua, no recuerdo ya, pero era complicado, era peligroso, claro que muy entretenido para un alma aventurera, por lo menos yo de chica era como bien aventurera. Pero eso, estudiar no fue tanto como trabajar ahí. En los primeros tiempos trabajar en educación multicultural, que fue uno de los primeros trabajos que hicimos, era como terreno abierto porque educación no sonaba a algo tan peligroso ¿te fijas?, como si se te hubiera ocurrido trabajar en política, eso sí que no, pero en educación, sobre todo si estabas trabajando con gente del Ministerio de Educación. 
AdS: Y después que terminaste la Licenciatura, ¿Cuáles fueron tus primeros trabajos?

En educación multicultural, estuvimos trabajando harto, trabajamos en toda la región, en ese tiempo eran provincias, pero trabajamos en lo que ahora es la región, yendo a las escuelas, hablando con los profesores, hablando con los apoderados, hablando con los niños, por todos lados. Especialmente con Héctor, no iba uno solo, íbamos en parejas y con varios antropólogos juntos. Ahí participaba René San Martín también, en los estudios y en el trabajo de terreno. También hicimos un trabajo en esa época para una congregación de curas norteamericanos, uno de esos curas había estudiado antropología con nosotros. Fíjate que es bien curioso, esa fue una cosa bien interesante, porque estos curas tenían un problema con los mapuche. Ellos eran misioneros, trabajaban con los mapuche, pero también con cuestiones económicas, o sea ellos le ponían plata al asunto, para ayudar, ayudaban a la gente pero con plata, con programas. En ese tiempo hicieron un programa de chanchos parece, una cosa muy curiosa, pero ahí conocí unos chanchos que parecían elefantes de grandes. $Y$ nosotros fuimos a ver cuáles eran los problemas que tenían, porque no podían llegar bien a las comunidades, no como personas ni nada de eso, sino que los planes no le resultaban muy bien. Y lo que pasaba es que estos curas eran tan modernizados, que no hablaban de evangelización, o sea ellos hablaban de las cuestiones económicas, de estos programas de ayuda social, y dejaron de lado todo lo que tenía que ver con el cristianismo, o más específicamente el catolicismo, entonces quedaron en el aire todas estas cuestiones religiosas formales e informales, porque hablando también la gente hace proselitismo, hablando en la conversa. Pues ellos se dedicaron a la parte económica y descartaron, por así decir, yo creo que de alguna manera consciente, toda la cuestión religiosa que era su tema, o sea ellos eran misioneros, eran evangelizadores, y lo dejaron de lado.

Ahí participé, me acuerdo fue un trabajo bastante largo, y también había un Liceo de Niñas, mira las cuestiones, había un Liceo de Niñas del campo, y la gente de la Congregación se preguntaba por qué las niñas que iban a ese Liceo, del campo a Chol Chol (era un establecimiento que estaba en Chol Chol), un internado; se preguntaban por qué se iban a Santiago a trabajar y no volvían a las comunidades, cuando el propósito era que volvieran informadas a las comunidades, educadas a la comunidades, educadas desde fuera ¿no? Y obviamente, porque allí las chiquillas tenían televisión, en ese tiempo la gente vivía todavía en rukas, ahora yo creo que ya no existe ni una, excepto en algún museo; andaban en carreta y toda la cosa, no todos, porque no hace tanto tiempo, pero, en fin. Y las niñas veían la tele, y a nosotros nos tocó hacer incluso entrevistas, encuestas y de todo con estas niñas, y las niñas qué querían tener, querían tener un pantalón Levis, por qué, porque tenían la tele, tenían a los gringos, entonces nada que ver, lo que tenían en el campo se les había quedado atrás y ellas querían estas otras cosas novedosas. Y solo bastaba con preguntarles, pero a nadie se les había ocurrido, entonces nosotros fuimos y les preguntamos. Y estuvimos ahí, vivimos ahí un tiempo también, íbamos con frecuencia, y así. Ese fue otro trabajo que hicimos, y te muestra el proceso, la historia como avanza. 
AdS: Fresia, la última pregunta para terminar esta fase, esta etapa de Temuco; Cómo fue el trabajo de la traducción del libro de Stuchlik "La vida en Mediería”, cómo fue ese proceso, qué te pareció y cómo llegaste a esa iniciativa de traducirlo.

Es que tenía el encargo de hace muchísimo tiempo, mucho tiempo; o sea, según recuerdo, Jarka me había dicho hace mucho tiempo, entonces lo tenía medio traducido, de hecho, lo empecé a traducir, me parece, cuando estaba embarazada de mi primer hijo, que ahí estuve cesante porque estaba en la Universidad Austral y me echaron. Mira, para que veas la época, en ese tiempo a mí me echaron de la Universidad Austral, donde me había ido con René San Martín, porque enseñaba a los alumnos a pensar, con eso te digo todo. Esa fue la acusación que me hicieron.

\section{AdS: ¿De qué año estamos hablando?}

¿'79?, '79 sí, porque mi hijo mayor es del '80. 1979, y yo estaba embarazada, me hicieron un juicio para echarme. Por el hecho de estar embarazada había una ley después de todo, que no podían echar a las embarazadas así no más, entonces me hicieron un juicio y nadie quiso tomar el caso, en Valdivia, mi padre habló con gente de Valdivia y no quisieron tomar el caso. Pero la idea es que en ese tiempo no se podía enseñar a la gente a pensar. O sea, esto sí que es solipsista, pero es que es tan interesante: uno de mis mentores es Magritte, René Magritte, disculpen el francés, pero es que tengo la garganta medio mala, René Magritte, que pinta para que la gente piense, o sea te das cuenta...
AdS: Bueno, ahora viene todo el periodo de lo que significa tu llegada a Santiago, y lo que significa la participación en la Universidad Bolivariana, y lo que es la Escuela de Antropología de esa universidad. Que surgen, si no nos equivocamos, en el año '92 casi junto con Antropología en la Academia de Humanismo Cristiano. Y lo que significó ese proyecto, y lo que significó también con posterioridad, que tú lo explicas muy bien en el libro, todo ese trabajo que comenzaron a realizar con el barrio Yungay y que va a llevar a esta línea muy interesante que se arma ahí, de trabajo de antropología urbana, de antropología barrial, como lo señalas ahí. Pero además una antropología que, ahora entendemos mucho más y un poco a partir de lo que explicabas en la primera parte, una antropología que está directamente vinculada con los sujetos y que se plantea también desde un punto de vista colaborativo, no es una investigación de lejos. Y lo otro es el tema de esta antropología caminante que tú haces todo el rato mientras estás por Yungay, que es muy interesante y que nos gusta mucho también, pero partamos por tu llegada a Santiago y la Bolivariana.

Mira, en Santiago, para hacerte una síntesis, porque ya he hablado mucho, mucho rato de mi misma, la llegada a Santiago desde el punto de vista del trabajo significó empezar a hacer una colaboración con una muy querida amiga que es Cecilia Dockendorff, socióloga, doctorada en sociología, pero también con Bachillerato en Antropología y una maestría en Antropología. O sea, es socióloga antropóloga, o socióloga antropológica, algo así. Bueno con Cecilia estuvimos trabajando en solidaridad, después de haber llegado aquí a Santiago. Y 
es un tema maravilloso, yo creo que ahí hice uno de los trabajos más lindos de toda mi vida, porque conocí a buena gente, o sea la mirada ética es para mí ultra importante, o sea es uno de los pilares de esto. Entonces, conocer a esa buena gente que hacía solidaridad en Chile y en el extranjero, incluso en relación con Chile, fue una de las maravillas de trabajo de mi vida, de las mejores cosas que yo creo haber experienciado no solo de la carrera o de la práctica profesional, sino que de la vida en general. Así que empecé por eso, y Cecilia me contactó con Bernardo Arroyo, que era el director de la Escuela de Antropología de la Bolivariana, él la había fundado, ya estaba cuando yo llegué, o sea yo llegué como en el segundo o tercer año, una cosa así, haciendo algunas clases, y fue por eso, porque trabajando con Cecilia, ella le dijo a Bernardo mira aquí está la Fresia, qué sé yo. Bernardo había sido alumno mío en Temuco así que me conocía y ahí empecé a trabajar en la Bolivariana. Ahora, fíjate que yo noté aquí como importante, en el desarrollo de la antropología en la Bolivariana, la multiplicidad de miradas, creo que eso fue el interés nuestro. También fue muy colaborativo ese trabajo, con el resto del staff de profesores en general, y después de ayudantes que había; fue un trabajo que trataba de integrar no una línea, sino que el máximo de líneas posibles. Entonces había profesores que eran aplicados, que eran más teóricos, que eran marxistas, que eran culturalistas, que eran qué sé yo, cuantitativos, cualitativos, te fijas, entonces había muchas líneas teórico metodológicas, eso era lo que nos interesaba a nosotros.

O sea, una integración de miradas, de teorías o de interpretaciones, que dijeran más de aquello que interesaba estudiar, o que interesaba comprender, no desde una sola línea, sino que desde esta amplitud que tenía ya la antropología desde hace mucho tiempo. Yo creo que eso fue el punto más importante en el desarrollo de esa antropología bolivariana. Entonces cabía todo aquello que fuera propio de la antropología en general, o sea de la antropología social o cultural en general, sin restar, había discusiones ahí por supuesto, pero no era una cosa de decir no, lo que yo pienso es lo verdadero. Obviamente que los profesores teníamos nuestras propias miradas, pero la idea era conjugar, o sea darles a los alumnos una mirada conjugada, integrativa. Aunque la idea de antropología integrativa, bueno el concepto de antropología integrativa después se transforma con Agustín Fuentes y gente por el estilo, pero ese era el punto para mí, yo creo que esa fue la impronta. No sé si se notó, pero desde la docencia sí, desde los docentes más bien, sí era así, esa era la idea. Ahora, fíjate que yo creo que fue un desarrollo, yo noté aquí con esperanza, interés y esfuerzo, harto esfuerzo porque había muy pocos recursos, y finalmente después se vendió la Universidad, y la antropología pasó a ser una cosa que no tenía ni pies ni cabeza para la nueva gente de la Universidad.

O sea, no había el conocimiento, primero, ni el interés, segundo, por seguir adelante con esta disciplina, ni con esta carrera dentro de la propia Universidad. Yo ahí no sé cómo lo mirarían las autoridades, pero el cambio fue tan evidente, fue tan evidente desde dentro, desde las no autoridades, como los miembros de la Universidad como yo, como cualquiera así de ese nivel no más. Las autoridades quedaron por allá y nosotros por otro lado, versus lo que pasaba con los anteriores, como el mismo Pancho Vio, ponte tú, o Antonia Elizalde, que tenían una carrera, una historia de vida, una profesión que era afín, después ya se perdió eso. Pero esa es 
mi historia, así como sintetizada de la carrera de Antropología en la Bolivariana, que se inició con mucha esperanza, y con mucho esfuerzo, con la impronta etnográfica, yo creo que fue importante, no por mí, sino que, por el conjunto del staff, y terminó con el cambio organizacional. No es banal que primero fueran estas autoridades y después las otras, eso marcó un claro quiebre en la carrera. Hasta el punto en que llegó un momento ponte tú, en que sacaron a Bernardo, que era realmente no solo el fundador, sino que como el alma de esa antropología bolivariana, y quedamos ahí, quedé yo ahí prácticamente con la Secretaria, y después quedaron los que después habían sido ayudantes, porque nosotros teníamos, también por Bernardo, todo el interés de armar una Escuela, en el sentido propio, o sea, en el sentido de escolar, de académico, y se había instaurado también la figura de los ayudantes, y eso también desapareció, o sea los quitaron de un momento a otro. Entones fuimos quedando prácticamente solos y terminó por acabarse, no había de donde más agarrarse. Quizás si hubiéramos sido más vendedores, qué terrible decirlo, pero está bien que la gente venda también, sí. Pero no pasó.

AdS: ¿Muchos de esos ayudantes son los que te acompañaron en esta línea de trabajo en Yungay? Conocemos, entre otros, a Leo Piña, pero hay más gente.

Sí, bueno, fueron otros alumnos, porque yo creo que en ese tiempo el Leo, Alejandra Espinoza, Alejandro Reyes, que fueron mis ayudantes, ya estaban incorporados en otros tipos de trabajo, pero hubo alumnos de mis cursos que me acompañaron, o sea, fue también un trabajo colaborativo. Ellos iban, ellos hacían contactos también. No todos los contactos fructificaron, pero más o menos fue así. El Leo estuvo, fíjate, el Leo estuvo trabajando con gente de situación de calle y siguió hasta el día de hoy en eso, pero en otra investigación, no fue la del barrio. Claro, fue en el barrio, y un poquito más allá en el barrio Yungay, un poquito más allá, pero no fue esta misma del barrio Yungay que se publicó. Ese trabajo se hizo con otro colega que era un sociólogo, el libro iba a ser de dos partes, una sociológica propiamente, y la otra antropológica, que fue la que terminó publicándose sola. Y eso era inicialmente, eso era el plan digamos, y se inició con interés de gente del barrio, o sea ellos, ellas, empezaron a dar señales, a decir, ponte tú, que podíamos estudiar esta parte, qué pasaba con esto otro y así se fue armando. No fue un trabajo desde la academia, y se inició cuando nosotros nos trasladamos desde Las Condes a Santiago Poniente, y ahí empezamos a salir con los alumnos a recorrer el barrio, a ver dónde estábamos parados obviamente; o sea los antropólogos somos curiosos, había que saber dónde estábamos llegando. Por lo menos para mí, que soy provinciana todavía, tantos años que llevo aquí y sigo siendo provinciana, además que darte cuenta que allí estaba la calle Maipú, que era la calle del prostíbulo, yo me lo recorrí todo, creo que encontré dos, uno en Maipú y otro en otro lado, pero, o sea, era como un mito urbano. Entonces más interesante. Me metí a todas partes, a los restoranes picantes, a todo, a las ferreterías, a todo me metí, por curiosa también. Y ahí se fue armando esa etnografía que fue lo más entretenido que hay, hasta tuvimos algunos alumnos que eran de por ahí, que también colaboraron. Así se fue armando eso, o sea, de a poco te diría yo, con conocimientos así como esporádicos que después se fueron sistematizando, con colaboración de mucha gente del barrio, yo no te diría que fueron informantes, yo te diría que fueron 
colaboradores porque también se hizo bola de nieve, o sea uno me llevaba a otro y a otro, algunos me acompañaron, varios me guiaron, no están en el libro todos los que me guiaron, que fueron conmigo caminando para tal lugar a conocer a esta persona o a esta otra, y así. Nos faltó mucho, pero fíjate que es bien interesante que estaban también en el barrio la Universidad La República y El ARCIS².

En el ARCIS, yo tuve acceso tiempo después, se hizo un estudio del barrio donde se le hacía una crítica al Barrio Yungay escrito por mí y por Bernardo. Fue súper interesante, porque ellos decían, era un par de alumnos me parece, decían desde una mirada de teoría crítica, fuerte, decían que nosotros habíamos tomado la elite del barrio, yo creo que se fijaron en la reina del barrio, que era una señora que era nieta de Domeyko, encantadora por lo demás. Entonces a mí me gustó mucho ese trabajo crítico de los alumnos, por qué, porque ellos tomaron la parte que nosotros no alcanzamos a tomar, y a mí me parece que así se hace todo en la disciplina, no que yo me quede con la palabra, sino que los otros sigan, y si destrozan lo anterior perfecto. O sea, bien por ellos, bien por la disciplina. Ese trabajo no fue, hasta donde yo sé, no fue muy conocido. Pero a mí me habría encantado juntarlo al Barrio, al libro ese del Barrio, hasta le habría hecho un prólogo, feliz yo. Así es que así dio un fruto por ahí, este Barrio Yungay publicado.

AdS: Y ese tema del caminar, de la etnografía colaborativa, porque no sé si en Chile ha sido tan común, o por lo menos hasta hace un tiempo atrás, el que se realizara etnografía colaborativa, y tampoco esta etnografía de integración conurbana como tú lo hiciste, caminando, visitando a la gente, ya nos contaste un poco, de cómo te iba llevando de uno a otro, pero en el libro, efectivamente, hay un conocimiento muy profundo de las personas, de dónde viven ellas, de qué es lo que hacen; incluso de personas que no conocían de esta especie de junta de adelanto, el comité de adelanto del Barrio Yungay, pero que eran vecinos de hace mucho tiempo. Gente que siempre uno encuentra, que hay mucha gente que nunca participó en organizaciones, nunca fue a un Nguillatún en la ciudad, nunca fue a un Wetripantu, nunca hizo nada de eso, nunca se vistió de mapuche, pero son los más mapuche que hay, pero que viven en otra sintonía. Y también lo interesante de eso es cómo ustedes van descubriendo los límites de este barrio porque en algunos casos se dice que los límites son bastante precisos y tiene que ver con calles, pero en otros casos tienen que ver con las sensaciones de las personas, y eso un poco ustedes, 0 tú en particular, lo descubren caminando, y recorriendo y yo creo que se recorrieron ese barrio completo.

Totalmente, o sea casa por casa diría yo, había casas por descubrir y personas por descubrir. Pero sabes qué, que no fue solo del barrio, lo que pasa es que en Temuco, cuando estábamos en Temuco haciendo investigación, trabajamos mucho caminando, muchísimo, en el campo. Con Héctor recuerdo haber caminado de un pueblo a otro, por el camino rural, caminando... Porque, y ahí hay una cuestión teórica, una cuestión epistemológico teórica, ¿cómo conoce la gente su medio? En el campo, en ese tiempo, porque hoy día ya tienen camioneta, de verdad, camionetas blancas de preferencia ¿no?, pero ¿cómo conocían en ese tiempo? Había una monja que iba caminando, con su mochila al 
hombro o el bolso acá al lado; los carboneros que iban en las carretas, a paso de camino, de caminante, o los bueyes, los bueyes no andan corriendo por todos lados, o como se llame el correr de los bueyes. Nosotros caminábamos entonces, caminábamos tal como la gente lo hacía. La gente, a lo más en ese tiempo ya remoto, hacía dedo. Pero caminaba, esa era la forma, así es como tu conocías el mundo rural, por medio del caminar. Yo caminé, yo subí cerros igual que la gente de ahí, no andaba en camionetas hasta que nos dieron, no sé de donde salió esa donación, un jeep del año de la perísima, me acuerdo que Héctor Zumaeta aprendió a manejar, y quién era su copiloto, yo. Pasábamos así por los puentecitos de madera, pero todo el resto fue caminando. Por qué te digo teórico metodológico, porque es una impronta de realidad, si es que se puede hablar de ese concepto, de una manera unívoca no se puede, pero para la gente era su manera de conocer, y para nosotros, antropólogos, era lo mismo. Nosotros hacíamos el camino que hacía la gente, entremedio de los potreros, mojándonos en los ríos; alguna vez pasando a caballo, pero habitualmente era caminando. Debimos haber caminado kilómetros de kilómetros; no éramos necesariamente los antropólogos que llegábamos en, y digo los antropólogos, porque la mayoría en ese tiempo eran hombres, que llegábamos en vehículo. Alguna vez llegamos en vehículo y nos golpearon el vehículo, ¿te fijas?, porque éramos extranjeros ahí..., incluso me acuerdo de alguna vez que, bueno yo era bastante flaca, en general, y a la gente ahí le gustaba la gente más rellenita, no sé si será todavía, pero en ese tiempo, se reían de mí, se reían de mí porque yo andaba con una capucha cuando llovía y con unas botas y con no sé qué, y la gente se reía porque era curioso ver a estas personas de afuera, más encima flaca, joven, flaca, vestida de esa manera extravagante, sin poncho, sin manta, yo creo que hasta con paraguas andaba, no estoy segura, pero capaz.

Entonces el caminar no fue solo del barrio, fue el caminar de antes, del cómo conocer. O sea, si tu ibas, no sé, de Chol Chol a Temuco en micro, se te sentaba el viejo con el poncho encima, y tú te bajabas y caminabas igual que ellos. $Y$ aquí en el barrio fue natural, y en el barrio es un barrio pequeño, bueno no es tan pequeño, pero es pequeño, entonces ¿de qué manera tú conoces?, caminando, si pasas en auto no tiene sentido, pasas run, run y no ves nada. Fíjate tú, yo soy una persona enferma de los pulmones hace muchos años que me cuesta caminar, pero una vez trabajando en otra investigación con un psicólogo, el psicólogo me dijo, porque yo me debo haber quejado, que me costaba ir ponte tú a La Reina, a la Villa La Reina que estaba más arriba, porque me costaba subir; y me dijo que, (Sergio Arias se llamaba, nunca me olvidé), me dijo que había que sacarle partido, que era muy bueno caminar despacio ahora, porque uno tenía la posibilidad de ver los detalles, y esa posibilidad de ver los detalles significaba apreciarlos. Entonces eso es lo mismo que pasó con nosotros. Con nosotros en Temuco, en el campo, Trabajo de Campo era trabajo en el campo, no solo en la ciudad, en el campo, campo. Y aquí en el Barrio Yungay también, o sea, cómo conoces tú un barrio si no es caminando, conoces antropológicamente quiero decir, o etnográficamente si tú quieres. No hay otra posibilidad para mí.

AdS: Y eso les permitió a ustedes, en 
términos de una especie de genealogía de la antropología urbana en Chile, llegar a una línea distinta de lo que habían planteado por ejemplo los trabajos de Andrés Recasens o Claudio Cerda. Pero no había sido una línea muy destacada sino hasta que aparecen ustedes, y después lo que va a desarroIlar la misma Francisca Márquez, y que va a profundizarlo en parte en su vida en la Academia y luego en la Alberto Hurtado. Pero ¿cómo te ubicas tú en términos de los aportes que han conseguido hacer? Y digo ustedes porque no eres solo tú, sino que tú con el equipo de trabajo, cómo han conseguido hacer para caracterizar y diferenciar un poco este objeto de la antropología que tú la defines, no solo como antropología urbana, que no es solo antropología en la ciudad. Tienes una mención a Geertz, en algún momento, que dice que no estudiamos en aldea, pero tú dices no, también tenemos que estudiar las aldeas, y nuestras aldeas son los barrios. Hay una línea de comunalización también ahí en la visión que ustedes plantean de las relaciones que hay en los barrios, ¿cómo te ubicas tú en la genealogía de estudios de los barrios?

Fíjate que yo no sabría contestar eso, porque la verdad no le he dado esa mirada a ese posible aporte, o sea ocurrió. No sé en qué medida haya sido distinto, bueno obviamente fue distinto en un sentido, pero no sé si haya sido un aporte a destacar, no tengo la visión distante, me falta la visión distante porque si tú te fijas todavía lo estoy viviendo, entonces me falta esa necesidad de desapego que también es requisito en la antropología. O sea, tú estás súper apegado, pero también tienes que estar desapegado, entonces todavía a mí, fíjate, me falta ese desapego como para decir "ah, aquí está lo que nosotros hicimos y se diferencia", ¿te fijas?, todavía lo estoy viviendo mucho, con mucha pasión. Entonces me falta. Yo creo que lo que podría haber pasado es que a nosotros nos importó el contacto ese, ese contacto primigenio por así decir con la gente. O sea, más allá de la estadística que, por supuesto, no desecho en absoluto, más allá de la encuesta, más allá de la generalización, yo creo que para mí es como la impronta de la etnolingüística también, que tú puedes comprender una cultura por el trabajo con una persona.

Por supuesto ahí hubo muchas personas, en esos estudios barriales. Muchas personas con quienes se conversó, con quienes de alguna manera se convivió, con quienes se caminó. Entonces nuestro punto de vista, y con eso no te digo que esto sea lo diferente, insisto, yo no soy capaz todavía de hacer el desapego necesario, yo creo que lo que hubo allí fue ese interés por hacer lo que la gente hacía, o sea, estar ahí con la gente de alguna manera como la gente. $Y$ no creo que haya sido solo la Bolivariana, en algún momento yo me encontré, cuando todavía trabajaba en la Bolivariana, me encontré con algún alumno de cualquier otra universidad, que yo lo miré y dije este es antropólogo, que estaba en un negocito ahí que hacían esto de arreglar motores o echarle aceite a los motores o algo así, estaba con un compadre afuera, no eran negocios elegantes, estaba el maestro fierrero, y un compadre pelucón con el pelo amarrado atrás. No quiero decir nadie, sino que ese, con unos pantalones cortos, o sea, no sé cómo se llaman, ¿ya? pero claramente que no era de ahí. Estaba en la misma postura que el otro compadre, estaban los dos ahí medio acuclillados con el motor, hablando o preguntando, y el otro haciendo su trabajo y contestando. A la 
pura pasada yo dije este es antropólogo. Eso es, es como ponerse de cuclillas con el gallo que está de cuclillas, no haciendo la oración sino que trabajando ahí, o la señora que está recibiendo a alguien por la ventana, y tú te asomas a la misma ventana, es un poco como eso. Pero con la curiosidad obviamente disciplinaria, y con los fundamentos disciplinarios, que sean los de un interés mayor. Entonces es eso, yo creo que siempre ha sido un poco eso. Fíjate que incluso estoy pensando que Stuchlik hacía lo mismo, él caminaba en el campo, caminaba con la gente. De repente tenía por ahí en algún libro un relato de su caminar entrevistando a personas. O sea, tú no sientas a la persona, ya usted se sienta aquí, yo me siento acá y yo pongo la grabadora o lo que sea, y yo le pregunto y usted me contesta. No, el gallo va caminando y tú vas caminando también, así de simple. $Y$ en el barrio era, bueno si esta persona conoce el barrio, muéstreme el barrio que usted conoce, y el barrio que usted conoce es el barrio que usted conoce y el barrio que usted conoce es otro, y el otro, y así. O sea, son miles de barrios, miles de barrios que tú tienes que caminar, en una de estas pasar en auto, pero ahí runnn y se acabó el barrio.

AdS: Pero eso les permite llegar al tema de la multidiversidad que tu mencionas, que no es una mirada homogénea de los barrios y eso está muy agarrado y de esa manera llegas a eso. Hay varias preguntas más que tienen que ver con la especificidad que tú has descubierto, y que tú has podido vivir en tu trayectoria, de lo que vendría siendo esta antropología chilena. En el caso de lo barrial, por ejemplo, estaban los casos en Argentina, de Gravano que estaba haciendo eso, que casi en paralelo a como lo estaban haciendo ustedes, y también está el tema de lo que significa tu papel como mujer en la antropología, una antropología que dentro de todo tiene una participación femenina importante, pero es una antropología que, como muchas otras disciplinas, fundamentalmente ha sido realizada por hombres, y si bien ha habido grandes mujeres como que siempre está ahí el tema de género detrás. Hay una cantidad de mujeres importantes, yo creo que quizás en la antropología más que en otras disciplinas incluso, pero ahí también queríamos saber un poco tu visión de eso, un poco de la trayectoria de la antropología chilena, cómo la ves tú, y también cómo ha sido tu paso como mujer antropóloga por esta disciplina en este país.

Mira lo que anoté: "fe y esperanza" para la antropología chilena, fe y esperanza porque vengo de familias católicas viejas así que fe y esperanza, es también mi propia historia. Por qué, porque si la antropología no fuera lo buena que es, porque la gente que alguna vez fueron nuestros sujetos, colaboradores, se hacen antropólogos. Primero. O sea, eso me da fe y esperanza. Y lo otro, es que hoy día hay dos programas de doctorado aquí en Chile, el del Norte y el que está iniciando la Católica. Por qué. No es por nada, ¿te fijas?, no es por nada, entonces para mí queda eso como lo que es el futuro de la antropología en Chile, aparte de todos los otros antropólogos que somos nativos en ese sentido, que somos de aquí.

Estoy hablando de nativos, de pueblos originarios, y nativos de aquí chilenos, porque se inició como ustedes bien saben con antropólogos extranjeros. 
Y ahora respecto a la antropología y las mujeres, fíjate que es efectivo, creo que hay un estudio hecho en alguna parte por ahí, de la feminización de la antropología. Si cuando yo empecé en esa época eran más hombres, hoy día aparentemente son más mujeres, y eso tiene que marcar una impronta, tiene que marcar. Y, por otro lado, fíjate que de casualidades de la vida me tocó una vez hacer un curso de metodología en un programa que hay de magister, no sé si está todavía, hace años atrás, en la Chile de... cómo se llamaba, no de feministas, pero era feminista, de este Centro de Estudios de la Mujer, que hay en la Chile en la Facultad de Ciencias Sociales, que está en un subterráneo, de eso me acuerdo. Bueno y ahí me tocó estudiar, porque las chiquillas que me pidieron que hiciera ese curso, que eran puras mujeres, ahí eran puras mujeres, me tocó estudiar bastante lo de la metodología feminista. Eso me dio una mirada sistemática a todo aquello que tú me estás preguntando, de cuál es el papel de la mujer, porque, como les dije, la metodología ha sido como una línea que tuve que seguir por $A, B$ o $C$ razones, durante mucho tiempo. Entonces, me encontré con autoras que, claro, alguna vez había visto en libros, leído algo, pero que hablaban del papel de la mujer en la investigación desde el punto de vista metodológico, teórico- metodológico. $Y$ estoy pensando incluso en algunas españolas, no estoy pensando en las grandes mujeres del feminismo antropológico, sino que en otras también, que hablan del cuidado, y aquí me voy a poner no feminista, de género no más, y de género medio evolutivo, porque se dice que nosotras las mujeres tenemos esta y esta característica que son distintas a las de los hombres, en términos evolutivos estoy pensando no más, no estoy pensando en los prejuicios y eso. $\mathrm{Y}$ una de las características que esas mujeres metodólogas feministas planteaban era la del cuidado, o sea, un acercamiento cuidadoso, no quiere decir esto que los hombres no hagan eso, no, pero un cuidado, yo te diría, aunque salga, pero espantoso, o sea decadente o lo que sea, un cuidado, así como sororal maternal, ¿te fijas? Y lo digo no más, total qué me importa a mí, esto no me va a servir para el currículum ni nada, da lo mismo. Pero hasta eso hablábamos, ¿te fijas? Una cuestión que no está en la antropología que yo conocí hecha por hombres; no se habla de eso, y ahí se hablaba, se mencionaba, se publicaba. Que a mí me venía muy bien, me sentía muy identificada porque era una manera que en lo particular me hacía sentir esa complejidad de esa antropología etnográfica, si tú quieres, que se practicó, que practiqué también. Esas ganas de juntarme con la persona desde el respeto, y de repente no solo desde el respeto, del cariño, y de darle como un ambiente grato, no siempre fue así obviamente, pero un ambiente que ayudara a la confianza, donde tú no estabas haciendo estrategias ni manipulando, ni necesariamente tratando de obtener una información a como diera lugar, cosa que yo escuché alguna vez en antropólogos y antropólogas, sin distinción de género.

Entonces eso para mí es súper importante, una pasada breve por ese curso donde aprendí eso, y lo más curioso de todo es que, bueno no era tan curioso, pero a mí me pareció curioso, que en ese curso que me tocó había solo mujeres, entonces era una conversa. Cuando yo llegué ahí, yo me acuerdo, pucha, dije yo, es como un colegio de puras mujeres esta cuestión, profesoras mujeres y alumnas puras mujeres. Me pareció rarísimo, pero después terminé gozándolo, o sea, era una conversa, 
bueno, yo siempre hacía como talleres en las clases, no eran tan catedráticamente hablando, sino que eran más en círculo conversando un poco. $Y$ fue bien rico, fue bien rico finalmente esa pasada por ese ambiente femenino, no te digo que todas fueran amorosas, ni yo tampoco, pero había ahí una energía, por así decir, que era femenina, no te digo feminista, femenina. Eso no sé si se nota en la antropología chilena.

Pero claro la antropología fue una pasión, creo que todavía. Entonces ¿qué era lo que pasaba ahí? ¿qué era? Fíjate que esto es una cosa curiosa, que los construccionistas o constructivistas chilenos, no sé si los otros, pero chilenos, así como esas miradas feministas femeninas, o femeninas feministas mejor, faltan en una cuestión bien importante y aquí sí que termino con lo de la etnografía, faltan ambos. Y yo, acuérdense, soy profesora de castellano, sé leer, de las poquitas cosas que sé, es leer, entonces en la lectura de los textos de estos constructivistas y de las femeninas feministas falta la esencia. Los constructivistas construccionistas escriben como si fueran del siglo XIX, ¿te fijas? escriben desde la tercera persona, o del nosotros primera plural, es una cosa inconcebible, y las feministas femeninas escriben igual como si fueran cualquier otra persona. Un científico, y le pongo "un científico", que está escribiendo en el siglo XIX o antes, o sea, el grapho de lo etno queda pendiente, te fijas, hay una escritura que no condice con la teoría, o no condice con la metodología. De dónde estamos hablando. Fíjate que Salas en los años de la perísima, o sea los años '70, nos decía, pero si el "nos" y la tercera persona del singular están obsoletos, hay que hablar desde el yo, porque soy yo quien estoy escribiendo, entonces por qué si soy yo la persona que estudió, la persona que escribe, por qué "yo" le pongo "nosotros", porque le pongo el no sé qué, el investigador, que soy yo misma. Entonces esa cuestión para mí es un punto que tiene que ver con la etnografía, y que de alguna manera se aliviana, se recupera, se soluciona, no sé si bien o mal, con la autoetnografía que se hace desde un yo presente, explícito, que es la forma en que nosotros conocemos, o sea, los antropólogos, las antropólogas o les antropologues, como ustedes quieran. ¿Cómo conocemos? No solo de los libros, sino que de nosotros mismos, de estar ahí, si tú quieres del caminar. ¿Quién es el que gasta los zapatos? ¿A quién le duelen los pies? ¿Quién tiene que ponerse un sombrero para cuando hace mucho sol, o sacarse el chaleco? yo misma, tú, tú, te fijas. Entonces, por qué si esa es nuestra forma de conocer, y estoy pensando en Rousseau, en Descartes, en cualquiera que haya hablado respecto de investigación profunda o lo que sea, cómo escribo yo, cómo digo eso que conozco, cómo manifiesto mi forma de conocer. $Y$ nosotros estamos errados en eso en Chile, o sea manifestamos nuestra forma de conocer de una manera que no corresponde a lo que estamos pensando, a nuestra orientación o pseudo orientación teórico metodológica, epistemológica, lo que sea, óntica, ¿te fijas? Si yo digo la realidad no existe, hay miles de realidades. O digo qué sé yo, que todo es una construcción, y después escribo los antropólogos de Chile piensan que no sé qué, no sé cuánto, y le pongo una encuesta. Está bien la encuesta, porque también son maneras de expresar lo conocido, pero pucha, ese es un reclamo que tengo de la antropología chilena, a lo mejor la sociología es lo mismo y etc., no sé, pero eso es un reclamo para mí que está en la obsolescencia. Y ahí es la cosa de la etnografía, en la parte del graphos, de la escritura, te fijas; obvio que tú no le puedes escribir así al Ministerio de Salud, depende del 
público, pero si estás aquí en una revista de antropología, pero si tu escribes en una revista especializada, donde todo el mundo sabe que tú conoces de esta manera y que tienes esta mirada, este enfoque, este acercamiento qué sé yo, iy sigues escribiendo como en el siglo XIX!

AdS: Pocas personas en Chile hablan de la autoetnografía todavía, y sabemos que es algo que se ha desarrollado en otros lados, tiene una versión gringa, tiene también unas mexicanas, con Mercedes Blanco, extraordinario todo lo que han hecho, pero acá en Chile no es mucho lo que ha aparecido de autoetnografía. Entonces, es interesante sobre todo por lo que tu planteabas de cómo los sujetos con los cuales nosotros trabajamos también pueden rever su propia existencia a partir de aportes antropológicos, y eso, evidentemente, debería dar o da en autoetnografía. Pero no solo en ellos y en ellas sino que también en nosotros, o sea posicionándonos, trabajando y liberándonos de este formato, como tu planteas, que es del siglo XIX, que es de una ciencia dura de la cual nosotros no estamos y ya hace rato que no deberíamos de estar ahí. Pero efectivamente, se nota a veces un estilo muy acartonado y muy cientificista para dar cuenta, y entendemos, no en el informe que entregas a determinados sectores, sino cuando hacemos trabajo para divulgar lo que hacemos desaparecemos y en ese sentido la autoetnografía es importantísima.

Es una antropología... claro, es una antropología igual, es una mirada. Pero aquí en Chile, por ejemplo, está Daniel Quiroz que tiene ese diario y también tiene unas etnografías mínimas, escribí una cosa, por eso sé que existen las Etnografías Mínimas, ese libro quiero decir, me llegó también el libro, y donde él mismo dijo una vez que eran ochenteros. Ellos tenían esa mirada, este grupo que era del Museo Precolombino...

AdS: Fresia, quizás la última para terminar, mira, estamos alucinados con tu entrevista, con tu visión de la antropología, nos puso nostálgicos, en cierto sentido, no sabemos si por recordar viejos tiempos, o porque este año hemos estado encerrados, pero al escucharte hablar de antropología caminante nos vino una nostalgia con esos trabajos de campo. Efectivamente, caminar esos caminos rurales, tomarse esas micros llenas a veces y con el señor con el poncho, o sea, recordamos todo eso, digamos esas fueron las cosas que nos marcaron. $Y$ entonces, a propósito de esto de la escritura y de la estandarización, porque somos antropólogos que vivimos en un medio donde necesitamos ganar un sueldo, que nos contraten etc., etc.; $y$ entonces frente a esa idea de antropología caminante pensamos que uno tenía más tiempo antes ¿no?, y entonces ahora vivimos en una época muy apurada, donde nos exigen publicar papers, lo primero que aparezca publicarlo, y entonces ese tiempo de reflexionar, de caminar, como que se pierde. Incluso hay muchas técnicas, hay consultoras que contratan etnógrafos para aplicar la técnica precisa y tener la información. Entonces, ¿cómo ves ese escenario actual para la antropología de publicar artículos indexados, paper, todo rápido, ganar proyectos e indicadores? 
Mira, sabes qué, que en algún momento participé en eso en términos de ganar proyectos, con la Bolivariana, en Temuco también lo hicimos, pero nos decían hagan esto, ustedes hagan esto ¿te fijas?, no era tan competitiva la cosa, y por lo demás en ese tiempo estábamos solos. Pero aquí sí, y yo creo que tiene pros y contras igual que todo en la vida. Por un lado, tiene el que impulsa a la gente a publicar, que es una pata ultra importante de la antropología, o de cualquier disciplina, y que a mí me faltó harto; y por otro lado tiene todo esto que se ha criticado bastante del apuro. Pero fíjate, que del apuro está la etnografía rápida ¿no cierto?, es de la Evaluación Rápida, y Handwerker, creo que se llama, el norteamericano este que escribe sobre etnografía rápida, y que tienen un método, eso lo pasábamos con los alumnos en la Bolivariana, un método en sentido estricto, no estricto en el sentido más bajo de la palabra; que dice el procedimiento específico, una especie de protocolo para investigar hasta en tres días. O sea, en tres días qué puedes conocer, o en un mes, en tres meses; que tres meses es harto ahora, pero antes era re poco, o sea, era un periodo de un año mínimo, ese era el periodo ideal en los antiguos tiempos. $Y$ yo creo que tiene la ventaja de que corresponde a los nuevos tiempos. La otra cuestión importante, que bueno, lo dejamos de lado, pero en la antropología chilena llegó a su cúspide con la gente de Temuco, con mucho orgullo lo digo, en el 2005, con Teresa Durán, Marcelo Berhó, Noelia Carrasco, cuando les publicaron una edición de un número de Antrophos, de la antropología interactiva que hacían en Temuco, o sea, no hay nada que se le compare a eso en Chile. En la antropología chilena, no hay. Es una creación, claro, de diferentes fuentes, pero una creación regional, local, de la Universidad Católica de Temuco, y de la Teresa Durán por supuesto.
¿Y en qué se parece eso a esto que estamos, a eso que preguntas? En que ellos hicieron una reflexión antropológica de la vivencia local- regional, e integraron a la antropología eso mismo que estaba ahí, o sea, el contexto. Integraron en una especie de necesaria completitud a la persona que investiga que es mi punto, al contexto sociopolítico, en ese caso con el pueblo mapuche, la parte colaborativa, la teoría antropológica que tiene, bueno ustedes pueden haber leído algunos de los textos de ellos, que tienen una serie de autores, entre ellos Stuchlik como antecedente, y lo que pasa aquí se le asemeja. Lo que dices tú se le asemeja en que nosotros como antropólogos, o ustedes ahora, tienen que hacer o ya han hecho probablemente, la reflexión respecto de cómo enfrentamos nosotros, o enfrentan ustedes, esos requerimientos del nicho en que vivimos, del medio. O sea, ¿cómo se hace? Por eso sale la etnografía rápida o esta investigación rápida. Cómo enfrentamos ese requerimiento, o sea, si eso es lo que se nos pide, qué hacemos nosotros como antropólogos ¿nos quedamos en el siglo XIX de nuevo? ¿O en la primera mitad del siglo XX? O avanzamos al siglo XXI. Entonces ¿cómo hacemos? Quizás, fíjate, esa reflexión no está hecha. Entonces cómo hacemos para lo que hicieron estos de Temuco, que se demoraron hartos años en desarrollar su antropología interactiva, no fue de un día para otro, ¿cómo hacemos para que esta premura no signifique el deterioro del conocimiento, la banalidad del conocimiento, la debilidad del conocimiento? Tiene que haber alguna manera, más allá incluso de lo que se ha hablado de la etnografía rápida o algo que sea de ahora ya 2020, 2021. 
Yo soy altamente partidaria de un meta análisis, o sea, sacándole partido a lo que se ha hecho. Qué se ha hecho, con qué temporalidad, cuáles han sido los resultados y sacar algo de ahí, sacarle partido a lo que se ha hecho, a la experiencia. Es un poco como lo que yo les decía de estos chiquillos de la ARCIS que hicieron un trabajo crítico del Barrio Yungay, es avanzar. A lo mejor no es del gusto de todos, pero si ese es el requerimiento de la antropología no puedes estar en una burbuja por allá en el aire, en la estratósfera ¿cierto? O sea, yo creo que sería bien interesante hacer eso, echarle una mirada a lo que se hace si es que hay acceso, en este tiempo precipitado, apresurado, que es lo que se impone hoy día. Seguramente hay gente que tiene harto tiempo, de hecho yo he colaborado en investigaciones, en dos investigaciones hasta el año pasado, cada una de tres años, tres años te das cuenta, seis años de una investigación más o menos seguida; era de Cecilia Dockendorff que trabaja el tema de la sociología de la religión, y que con la mayor gentileza me permitió colaborar con ella durante 6 años.
Entonces, unas investigaciones maravillosas, porque uno podría estar 25 años como los antiguos estudiando, y volver 25 años después a ver qué pasó 25 años después. Pero hoy día no se puede hacer eso, es un lujo. Es casi como otro mundo. Bonito sería, bonita idea.

AdS: Fresia, te damos las gracias realmente, estamos muy contentos con la entrevista y estas ideas que nos diste al final la verdad es que son... no lo habíamos visto así como lo planteas tú, así que nos prendes una ampolletita ahí, nos abre un camino, a veces estamos medio complicados con la realidad, pero aquí tú nos muestras otro punto de vista que me parece muy interesante la verdad es que hemos aprendido mucho hoy día contigo acá.

Muchas gracias, mi alma de profesora se siente absolutamente gratificada con tus palabras.

\section{Notas}

\footnotetext{
1 Junta Nacional de Auxilio Escolar y Becas.

${ }^{2}$ Universidad de las Artes y las Ciencias Sociales.
} 